\title{
Isolation and characterization of mesenchymal stem cells from human amniotic membrane
}

\author{
Silvia Díaz-Prado, Emma Muiños-López, Tamara Hermida-Gómez, Ma Esther \\ Rendal-Vázquez, Isaac Fuentes-Boquete, Francisco J. de Toro, and Francisco J. \\ Blanco
}

\begin{abstract}
Introduction: The human amniotic membrane is a highly abundant and readily available tissue that may be useful for regenerative medicine and cell therapy.

Aim: To compare two previously published protocols for the isolation of human amnion mesenchymal stromal cells (hAMSCs), including their phenotypic characterization and in vitro potential for differentiation toward osteogenic, adipogenic, and chondrogenic mesodermal lineages.

Materials and Methods: Human placentas were obtained from selected caesarean-sectioned births. Two different protocols (Alviano et al. ${ }^{1}$ and Soncini et al. ${ }^{2}$ ) for the isolation of hAMSCs were performed. After monolayer expansion of adherent cells from both protocols, the cells were characterized by flow cytometry and for multi- potentiality, as assessed by their capability to differentiate toward adipocyte-, osteoblast-, and chondrocyte-like cells.

Results: Both protocols yielded hAMSCs that showed plastic adherence, fibroblast-like growth, and welldefined human MSC markers. The cell yield and mesodermal differentiation capability of hAMSCs were higher in cells isolated using the Soncini protocol.

Conclusions: Our data demonstrated the successful isolation of hAMSCs from full-term placentas using two published protocols. Differences between the two protocols in cell yield and in vitro differentiation potential are shown
\end{abstract}

\section{Introduction}

According to a recent proposal of the International Society for Cellular Therapy, ${ }^{3}$ mesenchymal stem cells ( MSCs) are multipotent nonhematopoietic progenitors located within the stroma of the bone marrow and other organs that are phenotypically characterized by expression of several markers (e.g., CD73, CD90, and CD105) and the lack of expression of CD14 or CD11b, CD19 or CD79a, CD34, CD45, and HLA-DR surface molecules. ${ }^{4,5}$ They are isolated by adherence to plastic and expanded ex vivo. These cells have been shown to differentiate into multiple mesoderm-type lineages, including chondrocytes, osteoblasts, and adipocytes, ${ }^{6}$ and also into cell types of ectodermal (e.g., neurons) and endodermal (e.g., hepatocytes) origin. ${ }^{7}$

MSCs have been isolated from several tissues, including bone marrow, ${ }^{5}$ peripheral blood, ${ }^{8}$ adipose tissue, ${ }^{9,10}$ lung, ${ }^{11}$ liver, ${ }^{12}$ amniotic fluid, ${ }^{13-15}$ placenta, ${ }^{6,14-16}$ and umbilical cord. ${ }^{17}$

Some countries have private and public stem cell banks from umbilical cord blood for transplant programs or personal use. ${ }^{18}$

Bone marrow is the traditionally used tissue source of adult MSCs, in spite of some limitations. Among the most important limitations are accessibility and that the procedure required to obtain this kind of tissue is invasive and painful and there is a possibility of donor site morbidity, that the number of MSCs obtained is low, and that the potential to proliferate and differentiate diminishes as the donor's age in- creases. ${ }^{2,17,19,20}$ The identification of alternative sources of MSCs would be beneficial for both research and therapeutic purposes. The human amniotic membrane (HAM) contains two different cell types from different embryological origins $^{1,21}$ : human amnion epithelial cells (hAECs) derived from embryonic 
ectoderm, ${ }^{22}$ which form a continuous monolayer that is in contact with the amniotic fluid, and human amnion MSCs (hAMSCs), which are derived from embryonic mesoderm ${ }^{22}$ and are sparsely distributed in the stroma underlying the amnion epithelium. ${ }^{23}$ Bailo et al. ${ }^{24}$ isolated and characterized amniotic and chorionic cells from human full-term placentas, which suggested that both cell types may represent an advantageous source of progenitor cells useful for cell therapy and transplantation procedures.

Placental fetal tissues express only moderate levels of major histocompatibility complex class I and major histocompatibility complex class II antigens on its surface; therefore, hAECs and hAMSCs seem to be immune-privileged cells suitable for allotransplantation and regenerative medicine. ${ }^{19,25}$ Moreover, isolated cells have anti-inflammatory functions and nontumorigenicity, and do not require the sacrifice of human embryos for their isolation, avoiding the current controversies associated with the use of human embryonic stem cells. ${ }^{25,26}$ Given the minimal ethical and legal issues associated with HAM cell usage, further investigation into their functional potentials in vivo is warranted.

Published data suggest that HAM, an abundant and readily available tissue, is a very attractive source of MSCs. Indeed, the HAM is becoming appreciated as an alternative to bone marrow for adult MSCs for regenerative medicine. This tissue is routinely discarded postpartum, so it is easily procured, free from ethical problems, and available in abundance, providing efficiency in MSC recovery with no intrusive procedures. ${ }^{1}$ Harvesting cells from the HAM is noninvasive and safe. A major advantage of cells isolated from the HAM is that they are harvested after birth and can be cryogenically stored to be available in a timely manner for patient therapy after being thawed and expanded for use in tissue engineering, cell transplantation, and gene therapy.

HAM-derived cells are isolated from the full-term amnion after its manual separation from the chorion. Two protocols for cell isolation are described in the literature by Alviano et al. ${ }^{1}$ and Soncini et al. ${ }^{2}$ Briefly, Alviano's protocol involves three digestions (one mechanical and two enzymatic), whereas Soncini's protocol uses only two enzymatic digestions. Both protocols obtain hAMSCs, but no studies have compared their efficacy. In this study, we compare the two protocols for isolation of hAMSCs from the HAM. We also characterized the phenotypes of the isolated cells and assessed their osteogenic, adipogenic, and chondrogenic capabilities.

\section{Materials and Methods}

\section{Harvest and preparation of HAMs}

Human placentas $(n=12)$ from healthy donor mothers were obtained from selected caesarean sections at the Hospital Materno Infantil-Teresa Herrera from A Coruña, Spain. All the mothers gave written informed consent before collection. This study was approved by the Ethics Committee of Clinical Investigation of Galicia (Spain). Under stringent sterile conditions, the harvested placentae were placed in 199 medium (Invitrogen) with the following antibiotics: cotrimoxazol $50 \mathrm{mg} / \mathrm{mL}$ (Soltrim®; Almirall-Prodesfarma S.A.), vancomycin 50 $\mathrm{mg} / \mathrm{mL}$ (Vancomicina Hospira®; Laboratorio Hospira S.L.), amykacin $50 \mathrm{mg} / \mathrm{mL}$ (Amikacina Normon ${ }^{\circledR}$; Laboratorios Normon S.A.), and B amphotericin $5 \mathrm{mg} / \mathrm{mL}$ (Fungizona ${ }^{\circledR}$; BristolMyers Squibb). The HAM was carefully separated from the chorion, which was then discarded, and the amnion was immediately washed three to five times with $0.9 \% \mathrm{NaCl}$ solution to remove blood and mucus.

\section{Histological analyses}

For histological evaluation, 4-mm-thick paraffin sections were deparaffinized in xylol, rehydrated in a graded series of ethanol, and stained with hematoxylin and eosin (H-E) and Masson's trichrome ( MM) for HAM and chondrogenic examination and with toluidine blue (TB) and safranin $\mathrm{O}(\mathrm{SafO})$ for chondrogenic evaluation. 
An immunophenotypic analysis was performed to deter- mine expression of mesenchymal and hematopoietic markers in hAMSCs isolated using both protocols. For immunohistochemical evaluations, 4-mm-thick paraffin sections were deparaffinized and hydrated, and then incubated with monoclonal antibodies (mAbs) to detect type II collagen (Col II) (6B3 clone; Neomarkers) and cytokeratins (CK) 1, 2, 3, 4, 5, 6, 7, 8, 10, 13, 14, 15, 16, and 19 (AE1/AE3 clone; Dako). To facilitate the exposure of epitopes, the sections were pretreated with proteinase K (Sigma-Aldrich). The peroxidase/DAB ChemMateTM DAKO EnVisionTM detection kit (Dako) was used to determine antigen-antibody interactions. Localization of MSC-derived amniotic cells by immunofluorescence was performed using the antibody FITCCD44 (IM7 clone; BD Pharmingen). Negative staining controls omitted the primary mAb. Samples were examined using an optical microscope.

For the immunohistochemical evaluation of chondrogenesis, sections were incubated with antibodies to detect the presence of Col II (Neomarkers), and with a polyclonal antibody to detect aggrecan (C-20; Santa Cruz Biotechnology).

\section{Isolation and culture of hAMSCs}

Amnionic membranes were separately processed after the isolation protocols of Alviano et al. ${ }^{1}$ and Soncini et al. ${ }^{2}$ (Fig. 1). For Soncini's protocol, the HAM was cut into $\sim 2 \times 2 \mathrm{~cm}^{2}$ pieces and transferred into an enzymatic digestion buffer containing $2.4 \mathrm{U} / \mathrm{mL}$ of Dispase (Gibco) in phosphate-buffered saline and incubated at $37^{\circ} \mathrm{C}$ for $7 \mathrm{~min}$. The digested tissue was centrifuged and the supernatant was discarded. The tissue was then subjected to a second enzymatic digestion in RPMI 1640 (Lonza) culture medium containing $0.75 \mathrm{mg} / \mathrm{mL}$ type I clostridial collagenase (Gibco) and $20 \mathrm{mg} / \mathrm{mL}$ deoxy-ribonuclease I (DNAse I) (Sigma-Aldrich Quimica) for $3 \mathrm{~h}$ at $37^{\circ} \mathrm{C}$. After digestion, the resulting cell suspension was filtered through a sterile 70 $\mathrm{mm}$ filter (BD Biosciences) and the cells were collected by centrifugation at $200 \mathrm{~g}$ for $10 \mathrm{~min}$. The collected cells were designated as hAMSCs. The non-digested amnion fragments were incubated with $0.25 \%$ trypsin-ethylenediaminetetraacetic acid (EDTA) (Sigma-Aldrich) at $37^{\circ} \mathrm{C}$ for $2-3 \mathrm{~min}$. The cells were collected by filtration and centrifugation, as described above, and designated as hAECs, which were not used in this comparative study.

MSC FROM AMNIOTIC MEMBRANE

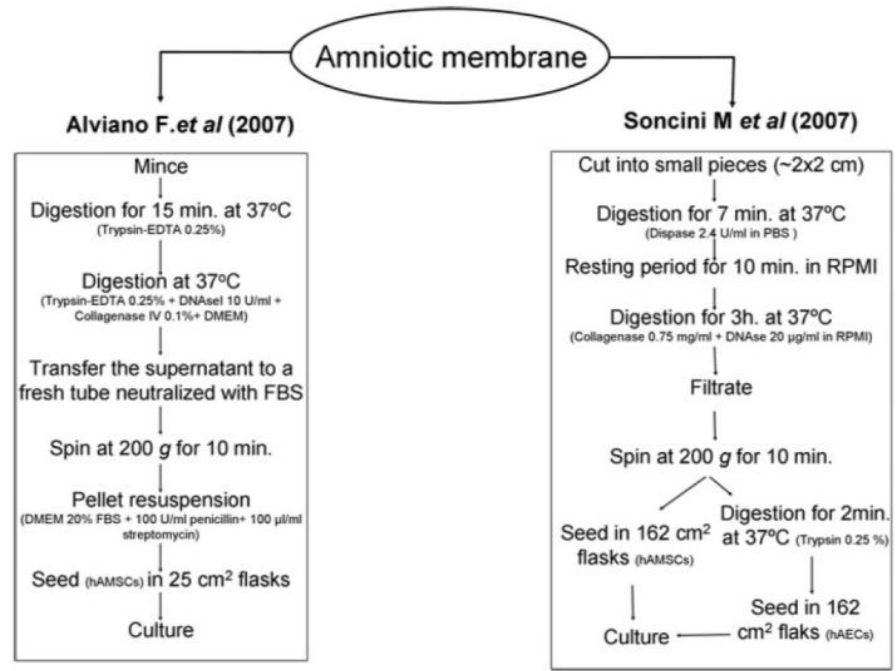

FIG. 1. Representative schematics of the two protocols used for hAMSC isolation. hAMSC, human amnion mesenchymal stromal cell 
For Alviano's isolation protocol, the HAM was subjected to a full mechanical digestion. Pieces of amniotic membrane were minced and subjected to two enzymatic digestions. The first enzymatic digestion used $0.25 \%$ trypsin-EDTA for $15 \mathrm{~min}$ and the second was in a digestion buffer containing $0.25 \%$ trypsin-EDTA, $10 \mathrm{U} / \mathrm{mL}$ DNAse I, and $0.1 \%$ type I clostridial collagenase in Dulbecco's modified Eagle's medium (DMEM) (Lonza) for 5 min until digestion was complete. In the meanwhile the fragments were pipetted vigorously up and down, avoiding foaming, and the super-natant was neutralized with $5 \%$ fetal bovine serum (FBS; Sigma-Aldrich) in DMEM.

The cell suspensions resulting from the digestions were centrifuged at $200 \mathrm{~g}$ for $10 \mathrm{~min}$. The cells were then resuspended in DMEM with $20 \%$ FBS and $1 \%$ penicillin- streptomycin (P/E) (Gibco) and seeded in $162 \mathrm{~cm}^{2}$ culture flasks for Soncini's and in $25 \mathrm{~cm}^{2}$ culture flasks for Alviano's isolation protocol. The hAMSC cultures were grown in a humidified $5 \% \mathrm{CO}^{2}$ atmosphere at $37^{\circ} \mathrm{C}$ until $70 \%$ confluent. The cells were recovered and expanded to obtain the appropriate number of cells for the experiments. Cells isolated from Alviano's protocol were plated until fourth to fifth passage, whereas cells isolated from Soncini's protocol were plated until second passage. Nonadherent cells were removed after $48 \mathrm{~h}$ of culture.

\section{Quantification of cells}

The number of hAMSCs isolated was counted using a Neubauer Chamber with cell viability assessed using $0.4 \%$ trypan blue dye (Sigma-Aldrich).

\section{Cell characterization by flow cytometry}

The hAMSCs were harvested by trypsinization, washed, and centrifuged at $300 \mathrm{~g}$ for $8 \mathrm{~min}$. The cells were counted and 2x105 cells were transferred to polypropylene tubes before fluorescence-activated cell sorting (FACS). The antibodies listed in Supplemental Table S1 were used for these experiments. Optimal amounts for the mAbs were determined and added to each tube for $40 \mathrm{~min}$ at $4^{\circ} \mathrm{C}$ in darkness. Most antibodies were conjugated with fluorescein isothiocyanate, phycoerithrin, or allophicocianine and were specific for the human markers associated with mesenchymal and hematopoietic lineages. When necessary, the cells were incubated for $30 \mathrm{~min}$ at $4^{\circ} \mathrm{C}$ in darkness with a secondary antibody to allow binding to the primary antibody. A control tube for each of the chromogens contained equivalent amounts of isotype standards. A minimum of 10,000 cell events per assay were acquired using a FACs Calibur flow cytometer (BD Biosciences). Data were analyzed using Cell Quest software (BD Biosciences). Statistical analysis was performed by the Mann-Whitney U test. The results are expressed as the mean \pm standard deviation of the percent of positive cells. Statistical significance was accepted at $\mathrm{p}<0.05$.

\section{In vitro differentiation studies}

Adipogenesis. hAMSCs from passages 0 to 4 and human bone marrow MSCs (hBMSCs) from passages 2 to 3 were detached using 2xtrypsin-EDTA solution (Sigma-Aldrich) and seeded at $1.5 \times 105$ cells $/ \mathrm{cm}^{2}$ into a one-well chamber slide in growth medium until confluent. Adipogenesis was induced by culturing in Bullekit Adipogenic Differentiation Medium (Lonza) for 21 days following the manufacturer's instructions.

Osteogenesis. hAMSCs from passages 0 to 4 and hBMSCs from passages 2 to 3 were detached using 2xtrypsin-EDTA solution and seeded at $1.5 \times 105$ cells $/ \mathrm{cm}^{2}$ into a one-well chamber slide in growth medium until confluent. Osteogenesis was induced by culturing for 3 weeks using hMSC Bullekit Osteogenic Differentiation Medium (Lonza). This culture medium was changed every 2-3 days.

For adipogenic and osteogenic differentiation assays, hAMSCs grown in DMEM medium, containing $20 \%$ FBS and P/E, were used as controls. hBMSCs were also tested for adipogenic and osteogenic differentiation, with their respective controls ( $\mathrm{C} \mathrm{hBMSCs}$ ) grown for 21 days in DMEM 21, as an adult MSC control. These controls were also evaluated histologically. Histological examinations were per- formed after cell fixation in $4 \%$ paraformaldehyde. 
To evaluate adipogenesis, the presence of cytoplasmic lipid droplets in the cultures was revealed by Oil-red $\mathrm{O}$ stain. To evaluate osteogenesis, the presence of calcium deposits in the cultures was determined using alizarin red stain ac- cording to a standard protocol.

Chondrogenesis. Chondrogenesis was assessed by micropellet formation. hAMSCs $(2.5 \times 105$ cells $\left./ \mathrm{cm}^{2}\right)$ from passages 0 to 4 and hBMSCs $\left(2.5 \times 105\right.$ cells $\left./ \mathrm{cm}^{2}\right)$ from passages 2 to 3 were detached using trypsin-EDTA and centrifuged at $300 \mathrm{~g}$ for $10 \mathrm{~min}$. The resulting pellet was cultured in chondrogenic differentiation medium containing DMEM with $15 \%$ FBS. This medium was supplemented with $5 \mathrm{mg} / \mathrm{mL}$ ascorbic acid, 1/1000 monotioglycerol, and 1\% P/E during the first 2 days to promote the induction of chondrogenesis. The medium was then replaced by DMEM with $15 \%$ knockout serum (Gibco) and 1\% P/E, and supplemented with 1 $\mathrm{mL} / \mathrm{mL}$ ascorbic acid, $10 \mathrm{mM}$ dexamethasone, $6 \mathrm{~mL} / \mathrm{mL}$ Transferrin, 1x107 M retinoic acid, and $1 \mathrm{ng} / \mathrm{mL}$ of recombinant human transforming growth factor-b3 (Prospec-Tany Technogene Ltd.) for 21 days. The medium was changed every 2-3 days. The micropellets were embedded in paraffin and the presence of hyaline cartilage-characteristic molecules was detected using the histological and immunohistochemical techniques. To evaluate chondrogenesis sections were stained with $\mathrm{H}-\mathrm{E}, \mathrm{MM}, \mathrm{TB}$, and Saf O. Also, immunohistochemistry studies were performed to detect the presence of Col II and aggrecan.

Quantification of positive histological staining (for alizarin red, Oil-red O, and Saf O) and immunohitochemistry staining (for Col II and aggrecan) was performed using analiSIS® software (version D) (Olympus).

\section{Statistical analysis}

All statistical analyses were performed using SPSS 16.0 software for Windows, p-values < 0.05 were considered statistically significant.

\section{Results}

\section{Localization of HAM-derived cells}

To determine the location of HAM-derived cells, healthy HAMs $(n=4)$ were examined histologically using H-E and MM staining, and by immunohistochemistry for Coll II and CK. The amnion consists of a single layer of ectodermally derived epithelium (EC), containing epithelial cells, (hAECs) uniformly arranged on the basement membrane (BM) (Fig. 2A, B). These epithelial cells are positive for the epithelial markers CK 1, 2, 3, 4, 5, 6, 7, 8, 10, 13, 14, 15, 16, and 19 (Fig. 2C). This epithelial monolayer of cells is located on the BM, which is one of the thickest membranes found in any human tissue. It is a collagen-rich mesenchymal layer, which also contains, according to previously reported studies, MSCs (hAMSCs) (Fig. 2D). Healthy HAMs were also stained by immunofluorescence for CD44 stem cell marker. Immuno- fluorescence results confirmed that hAMSCs from BM were positive for CD44 and therefore that BM contains cell having stem-cell characteristics (Fig. 2E).

\section{Morphologic and quantification studies}

After 2 days in culture, both protocols resulted in the isolation and culture of cells attached to the culture flasks with fibroblast-like cell morphology (hAMSCs) (Fig. 3). Quantitative studies showed that Alviano's protocol typically yielded 202,124 \pm 40,521 hAMSCs per gram of tissue $(\mathrm{n}=3)$, whereas Soncini's protocol yielded 2,009,990 $\pm 2,430,783$ hAMSCs per gram of tissue $(n=3)$ (Fig. 4) ( $\mathrm{p}=0.04$, Mann-Whitney $U$ test). In addition, the latter protocol not only yielded a greater number of cells, but also improved the growth rate of the resultant cells that reached confluency of $80 \%-90 \%$ in a week or less. 

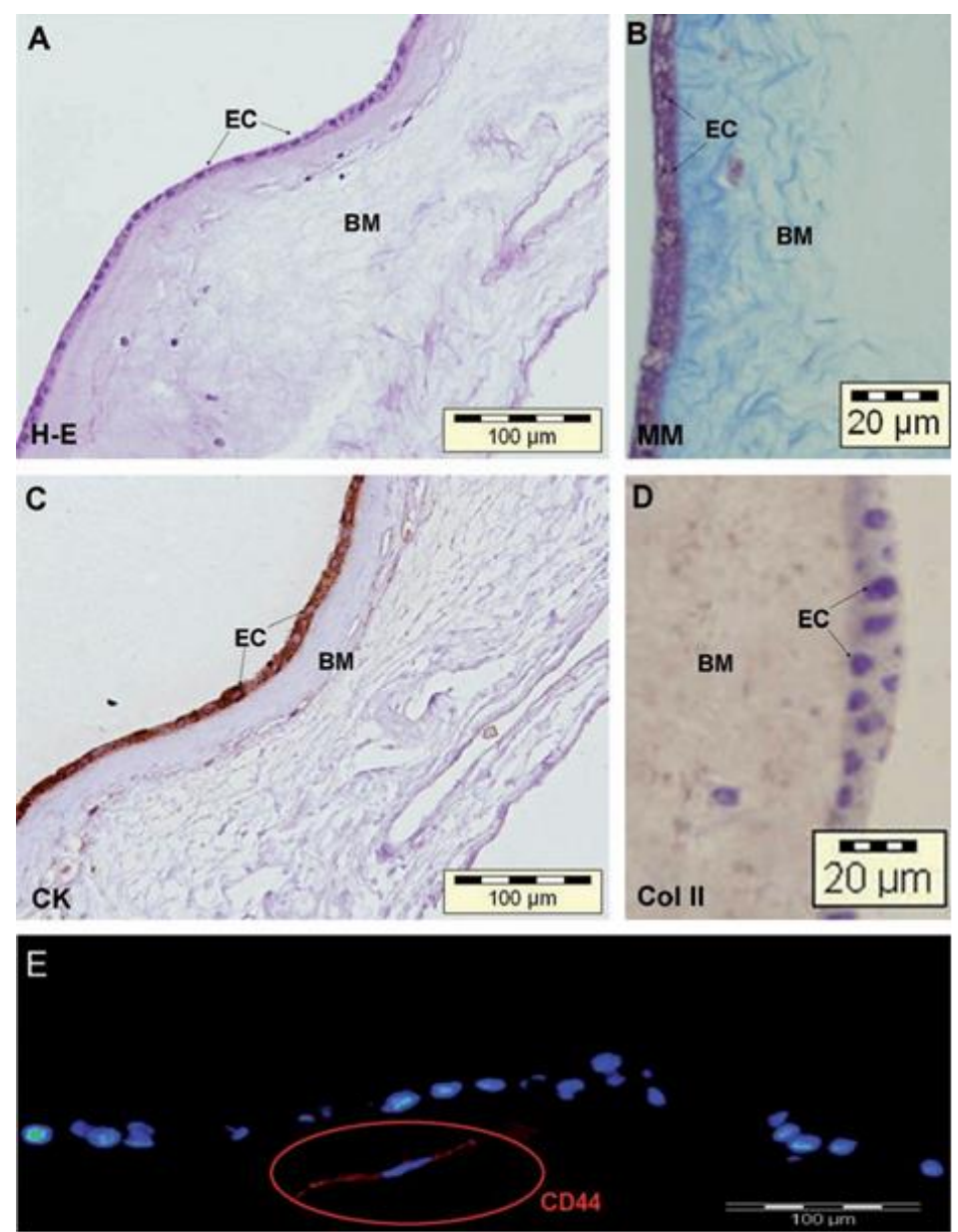

FIG. 2. Histological characterization of human amnion-derived cells. Sections of healthy human amniotic membrane $(n=4)$ stained with $(A)$ H-E and $(B)$ MM, by immunohistochemistry for (C) $\mathrm{CK}$ and (D) Col II, and by immunofluorescence for CD44 (E). BM indicates the thick basement membrane, and EC, the epithelial cells from the extra-embryonic ectoderm. H-E, hematoxylin and eosin; MM, Masson's trichrome; Col II, type II collagen; CK, cytokeratins.

\section{MSC FROM AMNIOTIC MEMBRANE}
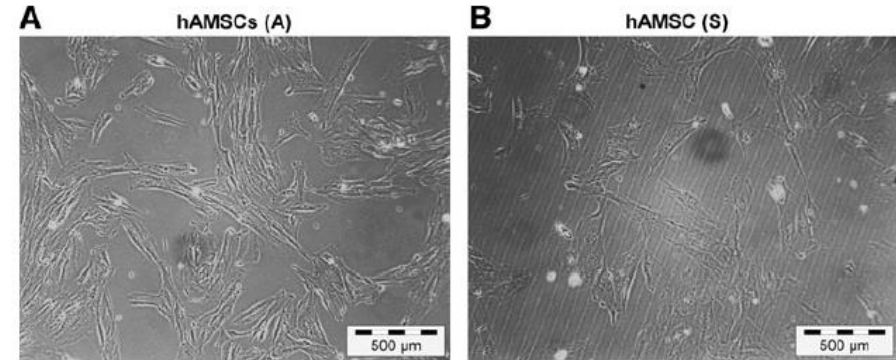

FIG. 3. Cell morphology of hAMSCs isolated using protocols of (A) Alviano et al.1 and (S) Soncini et al. ${ }^{2}$ Cultures of hAMSCs isolated using Alviano's protocol (A) show more fibroblast morphology than the same population isolated using Soncini's protocol (B). 


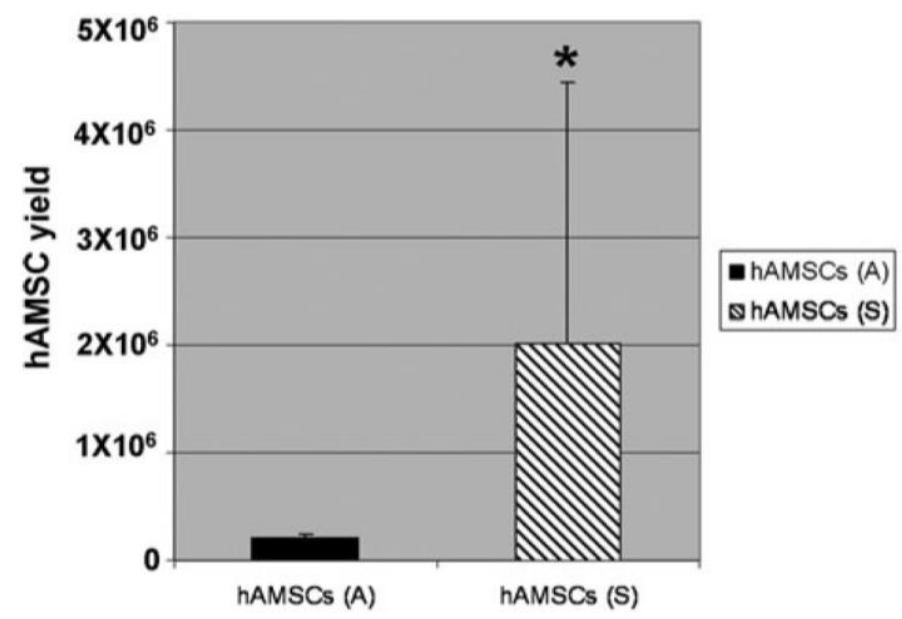

FIG. 4. hAMSC yields from the protocols $\mathrm{f}(\mathrm{A})$ Alviano et al. ${ }^{1}$ and (S) Soncini et al. ${ }^{2}$ Data are expressed as mean of the number of cells obtained per gram of amniotic tissue \pm standard deviation. ${ }^{*} \mathrm{p}<0.05$ (Mann-Whitney $\mathrm{U}$ test).

\section{Phenotypical characterization of hAMSCs}

FACS analysis demonstrated that of the expression levels of the different markers in hAMSC populations obtained from both protocols, only the marker CD117 showed statistically significant differences (Soncini: $22.79 \%$ vs. Alviano: 0.17\%; $\mathrm{p}=0.004$ ) (Table 1). hAMSCs from both protocols lacked any hematopoietic CD34 and CD45 markers and fibroblasts, indicating no contamination with hematopoietic stem cells from umbilical cord blood or embryonic fibroblasts.

This phenotypic characterization demonstrated that hAMSCs have a cell surface receptor pattern of expression that is similar to that previously reported for BMSCs, regardless of the protocol used (Table 1). Interestingly, we observed that hAMSC populations obtained using either protocol retained their phenotypic characteristics until at least nine passages.

Table 1. Analysis of Hematopoietic and Standard Adult Stem Cell Markers on Human Amnion Mesenchymal Stromal Cells Isolated Using Two Protocols

\begin{tabular}{lcc}
\hline Marker & (A) $\%($ mean $\pm \mathrm{SD})$ & $(\mathrm{S}) \%($ mean $\pm \mathrm{SD})$ \\
\hline & $73.95 \pm 29.77$ & $82.16 \pm 21.04$ \\
CD29 & $60.25 \pm 35.3$ & $76.11 \pm 20.16$ \\
CD44 & $46.38 \pm 34.9$ & $64.34 \pm 19.21$ \\
CD73 & $91.31 \pm 5.85$ & $88.49 \pm 11.49$ \\
CD90 & $29.44 \pm 32.07$ & $31.84 \pm 29.8$ \\
CD105 & $52.11 \pm 30.19$ & $44.37 \pm 27.72$ \\
CD166 & $0.17 \pm 0.14$ & $22.79 \pm 16.68^{\mathrm{a}}$ \\
CD117 & $0.8 \pm 1.43$ & $37.82 \pm 40.03$ \\
SSEA-4 & $0.23 \pm 0.005$ & $1.29 \pm 2.13$ \\
STRO-1 & $0.13 \pm 0.25$ & $0.17 \pm 0.39$ \\
CD34 & & \\
\hline
\end{tabular}

(A) Alviano et al. ${ }^{1}$ and (S) Socini et al. ${ }^{2}$ a p-Value $<0.05$ ( Mann-Whitney U test). SD, standard deviation. 
Isolated hAMSCs were cultured under specific conditions to perform functional differentiation assays. Specifically, we studied the potential of these cells to differentiate into adipocyte, osteoblast, and chondrocyte cell lineages.

Adipogenic differentiation was assessed by Oil-red $O$ staining after 21 days of culture in adipogenic medium (Fig. 5A, B). hAMSCs isolated with Soncini's protocol showed positive staining characterized by single adipocytic multivacuolar cells secreting lipid droplets. However, hAMSCs from Alviano's protocol produced almost no fat-containing cells. The percentage of Oil-red 0-positive staining cells was >50 times higher in hAMSCs isolated using Soncini's protocol than in hAMSCs isolated using Alviano's protocol ( $p=0.03$, Student's t-test). All cells maintained in the control medium showed an absence of lipid deposits.

A

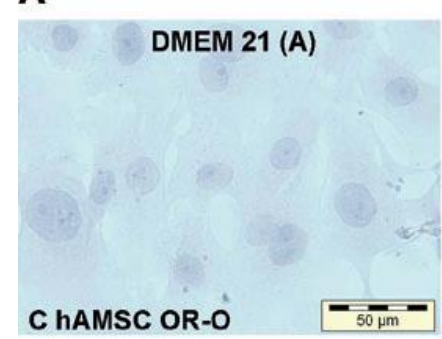

DMEM 21 (S)



C hAMSC OR-O

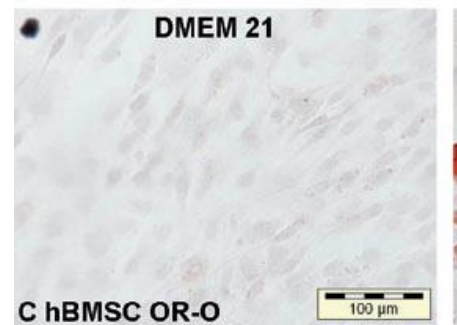

ADIPOGENESIS
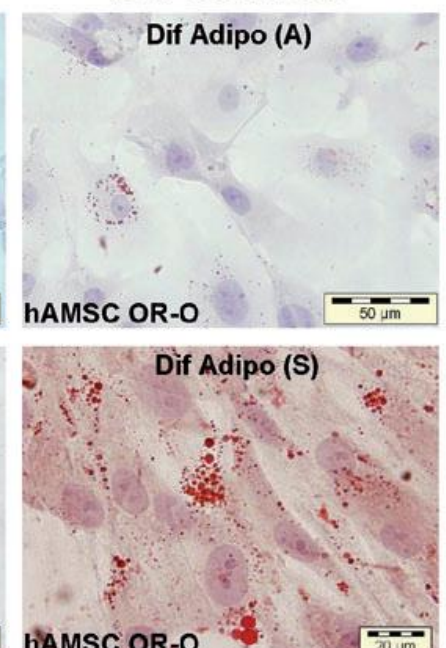

hAMSC OR-O

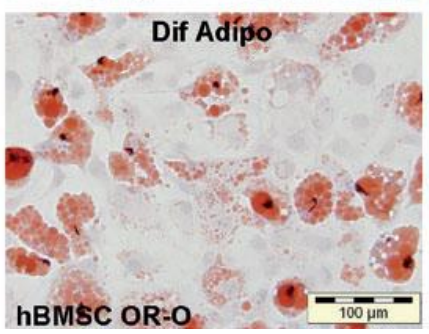


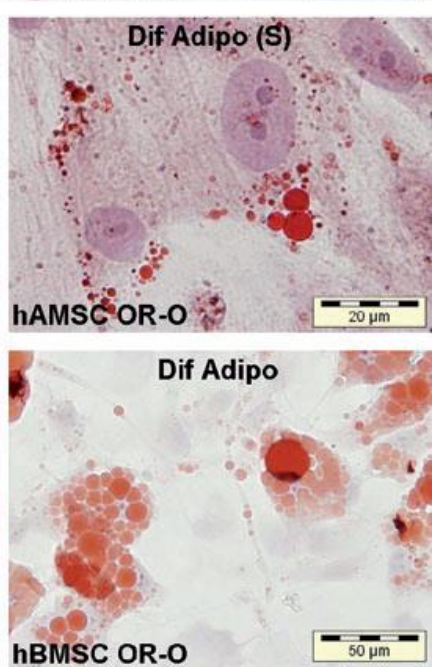

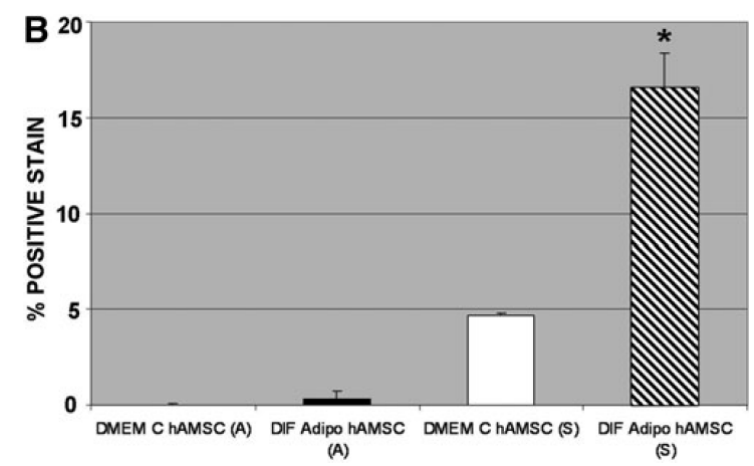

FIG. 5. In vitro adipogenic differentiation potential of hAMSCs isolated using protocols of (A) Alviano et al. ${ }^{l}$ and (S) Soncini et $a l^{2}$ hAMSCs isolated using two protocols, with their respective controls (C hAMSCs), were grown for 21 days in DMEM (DMEM 21). Adipogenic differentiation ("Dif Adipo") was determined by the presence of adipocytes with lipid drops detected using Oil-red O (OR-O) stain. hBMSCs were also tested for adipogenic differentiation, with their respective controls (C hBMSCs) grown for 21 days in DMEM 21 (A). The percentage of positive OR-0-stained cells is expressed as the mean \pm standard deviation $(\mathbf{B}) . * p<0.05$ (Student's t-test). DMEM, Dulbecco's modified Eagle's medium; hBMSC, human bone marrow MSC 
The osteogenic differentiation potential of hAMSCs was determined by the presence of calcification as shown by alizarin red stain (Fig. 6A, B). hAMSCs isolated using both protocols showed calcium deposition. Although the hAMSCs isolated using Soncini's protocol showed a percentage of alizarin red-positive-stained cells six-times higher than hAMSCs derived using Alviano's protocol, the difference was not statistically significant. The cells maintained in control medium showed practically no calcium deposits.

A

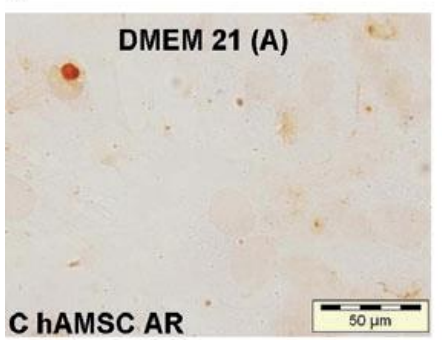

DMEM 21 (S)
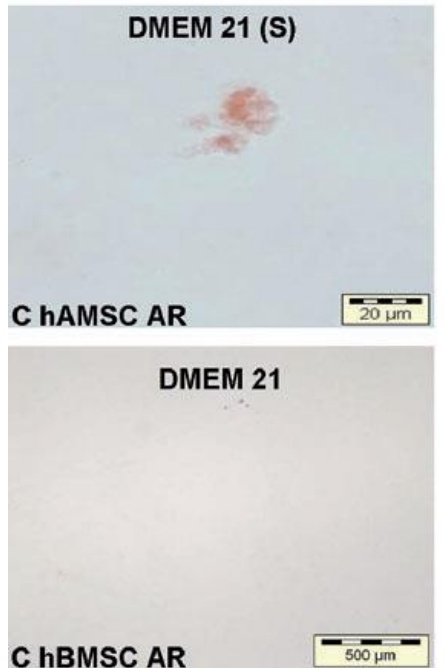

\section{OSTEOGENESIS}

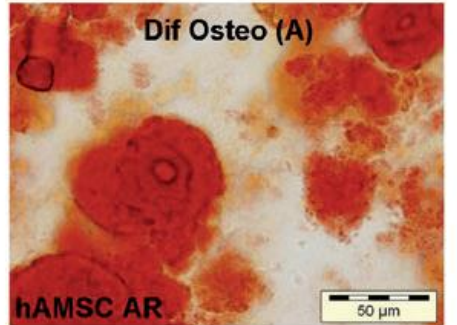

Dif Osteo (S)
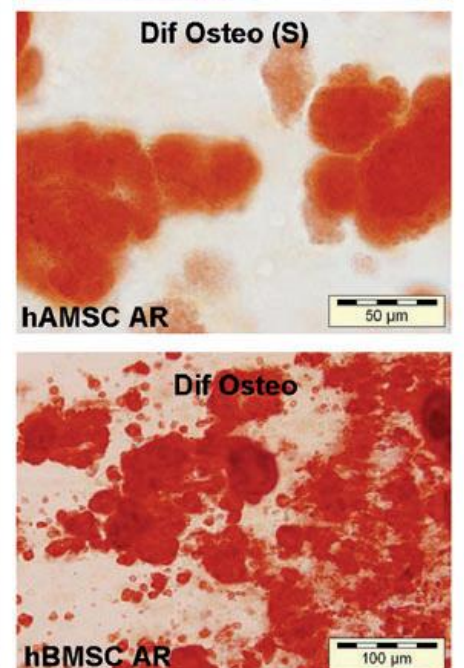

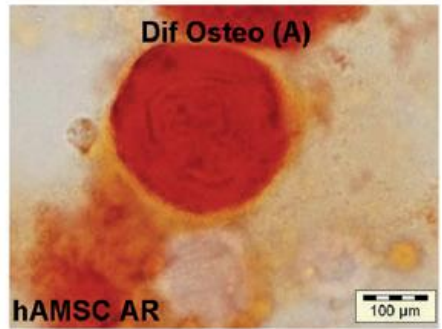

Dif Osteo (S)
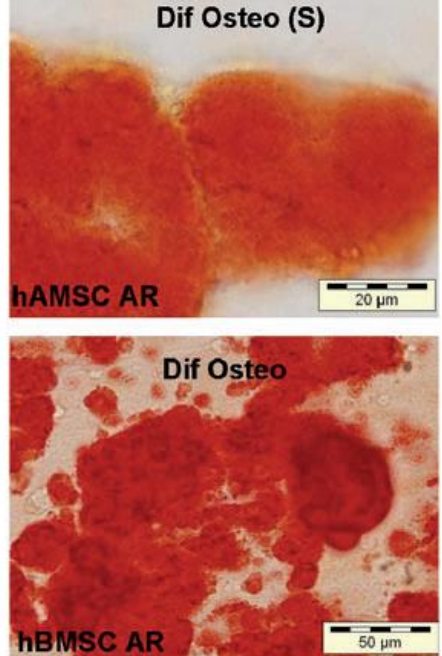

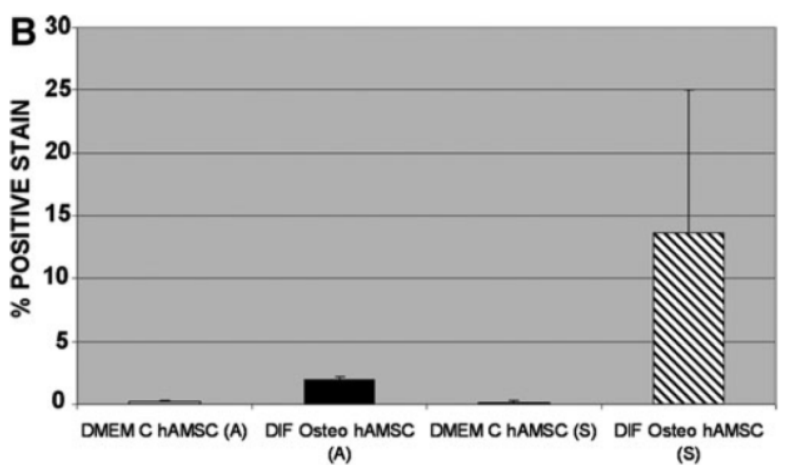

FIG. 6. In vitro osteogenic differentiation potential of hAMSCs isolated using protocols of (A) Alviano et al. ${ }^{1}$ and (S) Soncini et $a l^{2}$ hAMSCs isolated using two protocols, with their respective controls (C hAMSCs), were grown for 21 days in DMEM (DMEM 21). Osteogenic differentiation ("Dif Osteo") was determined by the presence of calcium deposits characteristic of osteoblasts detected by alizarin red (AR) stain hBMSCs were also tested for osteogenic differentiation, with their respective controls (C hBMSCs) grown for 21 days in DMEM 21. (A) The percentage of positive AR-stained cells is expressed as mean \pm standard deviation (B).

The chondrogenic differentiation potential of hAMSCs was determined by TB staining for proteoglycans, MM for collagens, and Saf O for glucosaminoglycans. The presence of Col II and aggrecans was detected by immunohistochemisry (Fig. 7A, B). Chondrogenesis was observed in all hAMSCs preparations that were isolated using both protocols. However, there 
were differences in the chondrogenic differentiation assays regarding on the protocol used for the isolation. In this regard, the percentage of positive staining for Coll II was statistically significantly higher in hAMSCs isolated using Soncini's protocol than using the Alviano's one. Coll II and proteoglycans were detected throughout the newly formed matrix, although immunodetection for Aggrecan was weak in most samples.

A


TB
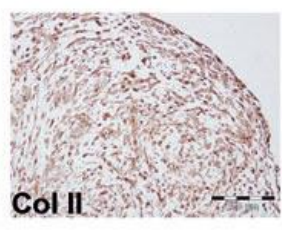

DIF hBMSCs
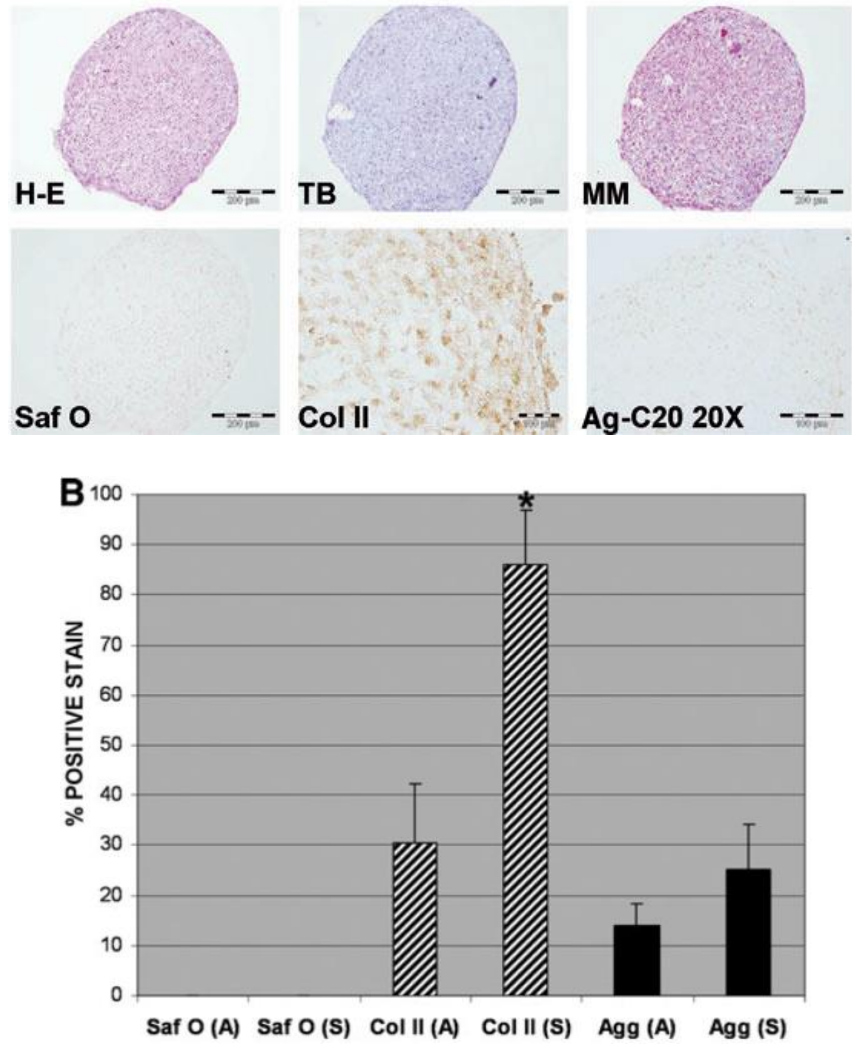


\section{Discussion}

The HAM is a thin semi-transparent tissue developed from extra-embryonic tissue consisting of both a fetal component, the chorionic plate, and a maternal component, the deciduas, composed of an epithelial monolayer, a thick BM, and an avascular stroma. ${ }^{25,27,28}$ The amnion is the inner fetal layer attached to the chorionic membrane. It consists of a single layer of ectoderm-derived epithelium uniformly arranged on the BM. The HAM has been widely utilized for plastic surgery, ophthalmology, dermatology, and gynecology procedures. ${ }^{29-33}$ Preclinical and clinical studies have demonstrated multiple uses for amniotic membrane stem cells in tissue repair, such as corneal tissue, ${ }^{34}$ spinal cord injury, ${ }^{35}$ brain infarction, ${ }^{36}$ and Parkinson's disease. ${ }^{37}$

This study provides a comparison between two protocols for isolation of hAMSCs, one developed by Alviano et al. ${ }^{1}$ and one by Soncini et al. ${ }^{2}$ The hAMSCs, isolated using either protocol, showed the adherence to plastic and fibroblast-like growth observed in MSCs from bone marrow. Further, immunophenotypic characterization of hAMSCs demonstrated the presence of common, well-defined human MSC markers previously described for BMSCs, CD90, CD44, CD73, CD166, CD105, and CD29, with the near absence of the hematopoietic markers CD34 and CD45, and the lack of fibroblast markers. ${ }^{38,39}$

This antigen expression pattern is consistent with data previously published for cells isolated from both the amnion and other regions of the full-term placenta. ${ }^{6,23,24,38,39}$ Although isolation and characterization of hAMSCs from the amniotic membrane have been performed by several independent researchers over the last few years, ${ }^{1,2,7,19,39}$ our results suggest that both Soncini's ${ }^{2}$ and Alviano's ${ }^{1}$ protocols yield MSCs from amniotic membrane, with some differences. A statistical analysis showed that the c-kit/CD117 marker was significantly ( $\mathrm{p}=$ 0.004) higher in hAMSCs isolated using Soncini's protocol, indicating that this protocol yields more hematopoietic progenitor cells than Alviano's technique. Our data also indicate that hAMSCs in culture express such markers of undifferentiated cells as SSEA-4 and STRO-1. Both of these embryonic stem cell markers were present in greater quantity in hAMSCs isolated from Soncini's protocol, perhaps indicating that this technique isolates cells in an earlier state of undifferentiation than does Alviano's technique.

In all HAMs analyzed, taking into account the amount of amniotic membrane used, the yield of hAMSCs isolated was always higher using the Soncini protocol. Therefore, Soncini's protocol allowed for the isolation and expansion of a larger number of cells in a very short time period. This ready and rapid availability of cells is one criteria required of a source of MSCs for it to be considered for cell trans- plantation.

Placental MSCs have been shown to differentiate into chondrogenic, osteogenic, endothelial, hepatocytic, myogenic, and neurogenic lineages, with appreciable differences in differentiation capability depending on the different fetal sources, placenta, chorion, or amnion. ${ }^{1,2,7,19,22,38-43}$ In this study, we performed functional differentiation studies to confirm that hAMSCs isolated from both compared protocols are in fact MSCs. We confirmed that hAMSCs isolated by both protocols can differentiate into osteocytic and adipocytic and chondrocytic lineages, indicating the presence of mesenchymal progenitors.

Finally, we found differences in the results from the two isolation protocols. A larger number of hAMSCs were collected using Soncini's protocol. A possible explanation could be that Soncini's protocol permitted culturing of both hAMSCs and hAECs by separation, whereas with Alviano's protocol both cell populations are cultured together. The effects of this mixed culture on cell proliferation and the isolation of MSCs are unknown.

In conclusion, our data demonstrate the successful isolation of hAMSCs from full-term placentae, using two previously published protocols. The protocols differed in cell yield, and isolated hAMSCs from the two techniques showed differences in the in vitro potential to differentiate into the main mesodermal lineages, but did not differ in immunophenotype.

\section{Acknowledgments}

This study was supported by grants from Servizo Galego de Saúde, Xunta de Galicia (PS07/84), Catedra Bioiberica de la Universidade da Coruña and Instituto de Salud Carlos III CIBER BBN CB06-01-0040. Silvia Diaz-Prado holds an Isidro Parga Pondal contract from Xunta de Galicia, A Coruna, Spain. Tamara Hermida-Gómez holds a contract from Fondo de Investigación Sanitaria (2008), Spain. Emma Muíños-López is supported by the Rheumatology Spanish Foundation, Spain. We thank M.J. Sánchez and P. Filgueira for technical assistance. 
Disclosure Statement

No competing financial interests exist.

\section{References}

1. Alviano, F., Fossati, V., Marchionni, C., Arpinati, M., Bonsi, L., Franchina, M., Lanzoni, G., Cantoni, S., Cavallini, C., Bianchi, F., Tazzari, P.L., Pasquinelli, G., Foroni, L., Ventura, C., Grossi, A., and Bagnara, G.P. Term amniotic membrane is a high throughput source for multipotent mesenchymal stem cells with the ability to differentiate into endothelial cells in vitro. BMC Dev Biol 7, 11, 2007.

2. Soncini, M., Vertua, E., Gibelli, L., Zorzi, F., Denegri, M., Albertini, A., Wengler, G.S., and Parolini, O. Isolation and characterization of mesenchymal cells from human fetal membranes. J Tissue Eng Regen Med 1, 296, 2007.

3. Dominici, M., Le Blanc, K., Mueller, I., Slaper-Cortenbach, I., Marini, F., Krause, D., Deans, R., Keating, A., Prockop, Dj., and Horwitz, E. Minimal criteria for defining multipotent mesenchymal stromal cells. The International Society for Cellular Therapy position statement. Cytotherapy 8, 315, 2006.

4. Mrugala, D., Dossat, N., Ringe, J., Delorme, B., Coffy, A., Bony, C., Charbord, P., Ha“ upl, T., Daures, J.-P., Noël, D., and Jorgensen, C. Gene expression profile of multipotent mesenchymal stromal cells: identification of pathways common to TGFb3/BMP2-induced chondrogenesis. Cloning Stem Cells $11,61,2009$.

5. Kastrinaki, M.-C., Andreakou, I., Charbord, P., and Papadaki, H.A. Isolation of human bone marrow mesenchymal stem cells using different membrane markers: comparison of colony/cloning efficiency, differentiation potential, and molecular profile. Tissue Eng Part C Methods 14, 333, 2008.

6. Barlow, S., Brooke, G., Chatterjee, K., Price, G., Pelekanos, R., Rossetti, T., Doody, M., Venter, D., Pain, S., Gilshenan, K., and Atkinson, K. Comparison of human placenta- and bone marrow-derived multipotent mesenchymal stem cells. Stem Cells Dev 17, 1095, 2008.

7. Pasquinelli, G., Tazzari, P., Ricci, F., Vaselli, C., Buzzi, M., and Conte, R. Ultrastructural characteristics of human mesenchymal stromal (stem) cells derived from bone mar- row and term placenta. Ultrastruct Pathol 31, 23, 2007.

8. Villaron, E.M., Almeida, J., Lopez-Holgado, N., Alcoceba, M., Sánchez-Abarca, L.I., Sanchez-Guijo, F.M., Alberca, M., Pérez-Simon, J.A., San Miguel, J.F., and Del Cañizo, M.C. Mesenchymal stem cells are present in peripheral blood and can engraft after allogenic haematopoietic stem cell transplantation. Haematologica 89, 1421, 2004.

9. Zuk, P.A., Zhu, M., Mizuno, H., Huang, J., Futrell, J.W., Katz, A.J., Benhaim, P., Lorenz, H.P., and Hedrik, M.H. Multilineage cells from human adipose tissue: implications for cell-based therapies. Tissue Eng 7, 211, 2001.

10. Zuk, P.A., Zhu, M., Ashjian, P., De Ugarte, D.A., Huang, J.I., Mizuno, H., Alfonso, Z.C., Fraser, J.K., Benhaim, P., and Hedrick, M.H. Human adipose tissue is a source of multi-potent stem cells. Mol Biol Cell 13, 4279, 2002

11. In’t Anker, P.S., Noort, W.A., Kruisselbrink, A.B., Scherjon, S.A., Beekhuizen, W., Willemze, R., Kanhai, H.H., and Fibbe, W.E. Nonexpanded primary lung and bone marrow-derived mesenchymal cells promote the engraftment of umbilical cord blood-derived CD34(b) cells in NOD/SCID mice. Exp Hematol 31, 881, 2003.

12. Le Blanc, K., Götherström, C., Ringdén, O., Hassan, M., McMahon, R., Horwitz, E., Anneren, G., Axelsson, O., Nunn, J., Ewald, U., Nordén-Lindeberg, S., Jansson, M., Dalton, A., Aström, E., and Westgren, M. Fetal mesenchymal stem-cell engraftment in bone after in utero transplantation in a patient with severe osteogenesis imperfecta. Transplantation 79, 1607, 2005.

13. You, Q., Cai, L., Zheng, J., Tong, X., Zhang, D., and Zhang, Y. Isolation of human mesenchymal stem cells from third- trimester amniotic fluid. Int J Gynaecol Obstet 103, 149, 2008.

14. Steigman, S.A., and Fauza, D.O. Isolation of mesenchymal stem cells from amniotic fluid and placenta. Curr Protoc Stem Cell Biol Chapter 1, Unit 1E.2, 2007.

15. Fauza, D. Amniotic fluid and placental stem cells. Best Pract Res Clin Obstet Gynaecol 18, 877, 2004.

16. Matikainen, T., and Laine, J. Placenta-an alternative source of stem cells. Toxicol Appl Pharmacol 207 (2 Suppl), 544, 2005.

17. Baksh, D., Yao, R., and Tuan, R.S. Comparison of proliferative and multilineage differentiation potential of human mesenchymal stem cells derived from umbilical cord and bone marrow. Stem Cells 25, 1384, 2007.

18. Samuel, G.N., Kerridge, I.H., and O'Brien, T.A. Umbilical cord blood banking: public good or private benefit? Med J Aust 188, 533, 2008

19. Wei, J.P., Nawata, M., Wakitani, S., Kametani, K., Ota, M., Toda, A., Konishi, I., Ebara, S., and Nikaido, T. Human amniotic mesenchymal cells differentiate into chondrocytes. Cloning Stem Cells $11,19,2009$.

20. Ilancheran, S., Moodley, Y., and Manuelpillai, U. Human fetal membranes: a source of stem cells for tissue regenera- tion and repair? Placenta 30, 2, 2009. 
21. Wolbank, S., Peterbauer, A., Fahrner, M., Hennerbichler, S., van Griensven, M., Stadler, G., Redl, H., and Gabriel, C. Dose-dependent immunomodulatory effect of human stem cells from amniotic membrane: a comparison with human mesenchymal stem cells from adipose tissue. Tissue Eng 13 , $1173,2007$.

22. Tamagawa, T., Ishiwata, I., Ishikawa, H., and Nakamura, Y. Induced in vitro differentiation of neurallike cells from human amnion-derived fibroblast-like cells. Hum Cell 21, 38, 2008.

23. Bilic, G., Zeisberger, S.M., Mallik, A.S., Zimmermann, R., and Zisch, A.H. Comparative characterization of cultured human term amnion epithelial and mesenchymal stromal cells for application in cell therapy. Cell Transplant 17, 955, 2008.

24. Bailo, M., Soncini, M., Vertua, E., Signoroni, P.B., Sanzone, S., Lombardi, G., Arienti, D., Calamani, F., Zatti, D., Paul, P., Albertini, A., Zorzi, F., Cavagnini, A., Candotti, F., Wengler, G.S., and Parolini, O. Engraftment potential of human amnion and chorion cells derived from term placenta. Transplantation 78, 1439, 2004.

25. Kim, S.S., Song, C.K., Shon, S.K., Lee, K.Y., Kim, C.H., Lee, M.J., and Wang, L. Effects of human amniotic membrane grafts combined with marrow mesenchymal stem cells on healing of fullthickness skin defects in rabbits. Cell Tissue Res 336, 59, 2009.

26. Toda, A., Okabe, M., Yoshida, T., and Nikaido, T. The potential of amniotic membrane/amnionderived cells for regeneration of various tissues. J Pharmacol Sci 105, 215, 2007.

27. Niknejad, H., Peirovi, H., Jorjani, M., Ahmadiani, A., Ghanavi, J., and Seifalian, A.M. Properties of the amniotic membrane for potential use in tissue engineering. Eur Cell Mater 15, 88, 2008.

28. Jin, C.Z., Park, S.R., Choi, B.H., Lee, K.Y., Kang, C.K., and Min, B.H. Human amniotic membrane as a delivery matrix for articular cartilage repair. Tissue Eng 13, 693, 2007.

29. Tejwani, S., Kolari, R.S., Sangwan, V.S., and Rao, G.N. Role of amniotic membrane graft for ocular chemical and thermal injuries. Cornea 26, 21, 2007.

30. Santos, M.S., Gomes, J.A.P., Hofling-Lima, A.L., Rizzo, L.V., Romano, A.C., and Belfort, R., Jr. Survival analysis of conjuctival limbal grafts and amniotic membrane transplantation in eyes with total limbal stem cell deficiency. Am J Ophthalmol 140, 223, 2005

31. Rinastiti, M., Harijadi Santoso, A.L., and Sosroseno, W. Histological evaluation of rabbit gingival wound healing transplanted with human amniotic membrane. Int J Oral Maxillofac Surg 35, 247, 2006.

32. Meller, D., Pires, R.T., Mack, R.J., Figueiredo, F., Heiligenhaus, A., Park, W.C., Prabhasawat, P., John, T., McLeod, S.D., Steuhl, K.P., and Tseng, S.C. Amniotic membrane transplantation for acute chemical or thermal burns. Ophthalmology 107, 980, 2000.

33. Morton, K.E., and Dewhurst, C.J. Human amnion in the treatment of vaginal malformations. Br J Obstet Gynaecol 93, 50, 1986.

34. Shimmura, S., and Tsubota, K. Ocular surface reconstruction update. Curr Opin Ophthalmol 13, 213 , 2002.

35. Sankar, V., and Muthusamy, R. Role of human amniotic epithelial cell transplantation in spinal cord injury repair research. Neuroscience 118, 11, 2003.

36. Sakuragawa, N., Misawa, H., Ohsugi, K., Kakishita, K., Ishii, T., Thangavel, R., Tohyama, J., Elwan, M., Yokoyama, Y., Okuda, O., Arai, H., Ogino, I., and Sato, K. Evidence for active acetylcholine metabolism in human amniotic epithelial cells: applicable to intracerebral allografting for neuro- logic disease. Neurosci Lett 232, 53, 1997.

37. Kakishita, K., Nakao, N., Sakuragawa, N., and Itakura, T. Implantation of human amniotic epithelial cells prevents the degeneration of nigral dopamine neurons in rats with 6-hydroxydopaminen lesions. Brain Res 980, 48, 2003.

38. Kobayashi, M., Yakuwa, T., Sasaki, K., Sato, K., Kikuchi, A., Kamo, I., Yokoyama, Y., and Sakuragawa, N. Multilineage potential of side population cells from human amnion mesenchymal layer. Cell Transplant 17, 291, 2008.

39. Mihu, C.M., Rus Ciuca , D., Sorita u, O., Susman, S., and Mihu, D. Isolation and characterization of mesenchymal stem cells from the amniotic membrane. Rom J Morphol Embryol 50, 73, 2009.

40. Portmann-Lanz, C.B., Schoeberlein, A., Huber, A., Sager, R., Malek, A., Holzgreve, W., and Surbek, D.V. Placental mesenchymal stem cells as potential autologous graft for pre-and perinatal neuroregeneration. Am J Obstet Gynecol 194, 664, 2006.

41. Tamagawa, T. Differentiation of mesenchymal cells derived from human amniotic membranes into hepatocyte-like cells in vitro. Hum Cell 20, 77, 2007.

42. In’t Anker, P.S., Scherjon, S.A., Kleijburg-van der Keur, C., de Groot-Swings, G.M., Claas, F.H., Fibbe, W.E., and Kanhai, H.H. Isolation of mesenchymal stem cells of fetal or maternal origin from human placenta. Stem Cells 22, 1338, 2004.

43. Sakuragawa, N., Kakinuma, K., Kikuchi, A., Okano, H., Uchida, S., Kamo, I., Kobayashi, M., and Yokoyama, Y. Human amnion mesenchyme cells express phenotypes of neuroglial progenitor cells. J Neurosci Res 78, 208, 2004. 
Supplemental Table S1. Antibodies Used for Flow Cytometry Cell Characterization

\begin{tabular}{|c|c|c|c|}
\hline Antibody & Specificity & Clone & Source \\
\hline R-PE-CD29 & $\beta 1$ Integrin & MAR4 & BD Pharmingen \\
\hline R-PE-CD34 & $\begin{array}{l}\text { Hemopoietic progenitor cell antigen } 1 \\
\text { (HPCA1) }\end{array}$ & 581 & BD Pharmingen \\
\hline FITC-CD44 & HCAM & IM7 & BD Pharmingen \\
\hline FITC-CD45 & Leukocyte common antigen (LCA) & $\mathrm{HI} 30$ & BD Pharmingen \\
\hline PE-CD73 & Ecto-5'-nucleotidase & AD2 & BD Pharmingen \\
\hline PE-Cy5-CD90 & Thy-1 & $5 \mathrm{E} 10$ & BD Pharmingen \\
\hline FITC-CD105 & Endoglin & SN6 & Serotec \\
\hline APC-CD117 & c-kit, SCFR & YB5.B8 & BD Pharmingen \\
\hline R-PE-CD166 & ALCAM & $3 \mathrm{~A} 6$ & BD Pharmingen \\
\hline Fibroblast & Fibroblast-specific antigen & $1 \mathrm{~B} 10$ & Sigma-Aldrich Quimica \\
\hline SSEA-4 & Stage-specific embryonic antigen 4 & MC-813-70 & R\&D Systems \\
\hline STRO-1 & Stromal antigen 1 & NS1-Ag4-1 & $\begin{array}{l}\text { Developmental Studies } \\
\text { Hybridoma Bank }\end{array}$ \\
\hline
\end{tabular}

